\title{
The Making of a Tropical Disease: A Short History of Malaria
}

\author{
by R.M. Packard \\ Baltimore, MD: The Johns Hopkins Univ. Press, 2009 \\ ISBN 978-0801887123 \\ Hardcover $\$ 24.95 ; 320$ pp.
}

\author{
Reviewed by Walter Kipp \\ Department of Public Health Sciences \\ University of Alberta \\ walter.kipp@ualberta.ca
}

This book provides an interesting overview and description of malaria, now a mostly tropical parasitic infection with an immense mortality and morbidity toll. Interestingly, the book is neither clinical nor epidemiological, as the author focuses on explaining malaria transmission, spread, and control from the perspective of social, economic, and specifically environmental factors. This gives the book authenticity, as it incorporates a true multisectoral approach to malaria control.

The introductory chapter lays out several case studies from different parts of the world, where the problematic complex nature of malaria transmission, spread, and control is explained. The problem here is that readers not familiar with malaria terminology will be lost, as some of the technical terms are only explained in the next chapter.

In Chapter 1 the malaria parasite cycle is explained, and also the vector; mosquitoes of the species "anophelines" are described as to their habits, breeding, and biting behaviour. The reader also learns that the malaria parasite has existed for a long time, probably since 20,000 BC. In this chapter, the author also outlines how the parasite and the vector have adjusted to human behaviour over this extended time period. One evolutionary adjustment of humans to the pressure of the malaria parasite described is the mutation of normal hemoglobin into $\mathrm{Hb} \mathrm{S}$, which is not susceptible to the parasite, but which causes sickle-cell anemia-the price we pay for protection against malaria. The author states that the evolution of malaria and its adaptation to humans happened in the African tropical forests and expanded from there to other parts of the world, most likely before 15,000 years BC.

Chapter 2 deals with the expansion of malaria from the African forests northbound into Europe. The author is able to make detailed links between malaria expansion and the human conditions. For example, he explains how the parasite was introduced into Europe from Carthago into Sardinia during the Carthaginian War, and how the importation of malaria infected North African slaves in the core 
of the Roman imperium. The malaria parasite was introduced from Europe to North America in the early days of the European settlers reaching North America.

Chapter 3 focuses on the North American continent and the role the civil war played in the United States, disrupting agricultural activity and leading to the blocking of irrigation canals due to lack of maintenance. The author makes a very strong argument here for the relationship between malaria transmission, agriculture (often irrigated), and the economic status of parts of the USA and its plantation workers. For example, the cultivation of rice in the US Midwest was done more on a commercial basis, with proper technology, than the sugar plantations in the South, where mostly slaves were doing the labor. This led to much higher rates of malaria transmission in the South, as the poor slaves were living in shacks and were not able to protect themselves against malaria.

Chapter 4 outlines the close relationship between malaria transmission and agricultural activity. Land cultivation is often combined with irrigation, which creates additional breeding spots for mosquitoes. Deforestation-an inevitable part of cultivation-renders the land more prone to flooding, which also increased malaria transmission.

In Chapter 5 the author describes the transition from broad-based views of malaria control using a multisectoral approach, which was very successful in Italy during the First World War. The availability of effective pesticides and the evolvement of modern technology shifted attention from the broad-based approach to selective technical intervention, like vector control of the anopheline mosquitoes. The author also describes that after WWI the UN split these roles between different players (WHO, ILO, FAO), with less emphasis on integrated programs.

Chapter 6 deals with the colossal failure of the malaria eradication program that was launched by the World Health Organization in 1955 and focused on DDT spraying. After some initial successes, the mosquitoes developed resistance against DDT, which rendered the spraying methods more and more ineffective. Not only did the malaria eradication program not achieve its objectives, it also demotivated the health services for malaria control actions for at least two decades.

In chapters 6 and 7 the author describes the malaria situation after the failure of the eradication program. In examples from USA, Swaziland, and the Amazon basin in Brazil, he continues to detail the complex relationship between malaria transmission, human behaviour, and environmental factors. He uses the example of a series of malaria epidemics in the 1980s in San Diego County, USA, based on a resurgence of malaria in Mexico and Central America due to the collapse of the eradication program, after which infected migrant laborers re-introduced malaria to this part of North America. He also cites as an example the massive colonization of the Amazon forest, which changed the flow of water, created more breeding sites, and destroyed wild animals (therefore mosquitoes were more likely to feed on humans). Another example of re-introducing malaria in parts of Pakistan was the humanitarian crisis in Afghanistan after the Russian invasion, where hundred thousands of Afghan refugees, living in the northern parts of Pakistan in camps under very poor and unhygienic conditions, brought malaria back to northern Pakistan. These conditions favored malaria transmission and caused a substantive increase of malaria in this part of Pakistan. 
The last chapter deals with a new malaria control program called "Roll Back Malaria," which focuses on an approach to integrate malaria control into the general health services, and pays attention to the specific needs of a particular area/ country. However, the author notes here that the flexibility of donor support for this program has been less pronounced than what originally was proclaimed. For example, a component of indoor spraying that was wanted by a number of countries, and which would have made sense, was not financed by this program.

Overall, this is a fascinating book about one of the world's most important tropical diseases, and the failures and successes of controlling it. Most importantly, the author shows in an exemplary manner how disease causation and transmission is so closely linked with human behaviour, the declining effectiveness of drugs and pesticides, misguided development policies, armed conflicts, population displacements, HIV/AIDS, the growing debt burden, collapsing health systems, and growing poverty.

In the book, some of the case studies are given in too much detail. This reader would have liked a shorter summary. The expansion of the malaria parasites $\mathrm{Pl}$. falciparum, Pl. vivax and Pl. malariae are well explained. However, the parasite Pl. ovale never left Africa, which makes the reader wonder why. No answer is given to this question. Also, the relationship between malaria parasites and the nutritional status of humans is not explained in much detail, so the reader unfamiliar with the medical sciences may have difficulty in understanding these relationships. What is largely missing, as well, is any discussion of malaria transmission and climate change. With warming temperatures causing extended rain periods, making it easier for the malaria parasite to grow and multiply, increased malaria transmission in future is most likely to occur.

In spite of these small shortcomings, I highly recommend the book, be it for the medical professional who is involved in global health activities, or for the lay person interested in tropical diseases, providing an extensive history of the disease evolution of malaria. The book strongly advocates a multi-sectoral approach to disease control as the only way for success. I fully agree with that perspective and I hope that this book will be successful in promoting this view to a broader audience. The author can be congratulated for having tackled such a complex and difficult topic. His research and depth of knowledge on the topic as a historian are just amazing. He has also provided excellent references for further studies. 